\title{
CUltura POPULAR: DO FOLCLORE AO PATRIMÔNIO ${ }^{1}$
}

\author{
Gilmar Rocha ${ }^{2}$
}

\begin{abstract}
Resumo
A análise da "cultura popular" nos possibilita um fecundo exercício de reflexividade epistemológica sobre o campo das Ciências Sociais no Brasil. Nesse processo, concebido como "histórico-estrutural", são identificados três sentidos a partir dos quais se pode estudar a formação conceitual da cultura popular, a saber: a sociologia do folclore, a ideologia política da cultura popular e a antropologia do patrimônio.
\end{abstract}

Palavras-Chave: Folclore. Cultura popular. Patrimônio imaterial.

\section{Popular CUlture: From FOLKLORE TO PATRIMONY}

\section{Abstract}

The analysis of "popular culture," as inspired by the proposal of the archaeology of knowledge, allows us to exercise epistemological reflexivity on the formation of the Social Sciences in Brazil. In this process, conceived as a "historical-structural" one, we can identify three perspectives from which popular culture has been

\footnotetext{
${ }^{1}$ Uma versão preliminar deste ensaio foi apresentada no XIII Congresso Brasileiro de Sociologia (2007), realizado na cidade de Recife (PE). Agradeço aos coordenadores do GT Sociologia da Cultura (Rogério Proença, Edson Farias e Maria Celeste), uma vez mais, o renovado estímulo intelectual, e aos participantes, as críticas e sugestões ao tema em pauta.

${ }^{2}$ Doutor em Ciências Humanas - Antropologia Cultural (IFCS-UFRJ). Professor de Antropologia do Departamento de Ciências Sociais da Pontifícia Universidade Católica de Minas Gerais.
} 
considered by the Social Sciences: the sociology of folklore, the ideology of popular culture, and the anthropology of patrimony.

Keywords: Folklore. Popular culture. Immaterial patrimony.

\section{UM CONCEITO TOTÊMICO}

"cultura popular" tem merecido a atenção dos intelectuais ocidentais desde
fins do século XVIII, momento em que a Europa viveu inúmeras e profundas
transformações em todos os níveis da vida social. Desde então, a divisão cultural entre o erudito e o popular se estendeu a outros níveis da realidade social, por exemplo, entre o rural e o urbano, o oral e o escrito, o tradicional e o moderno. Frente ao processo civilizatório, imaginado como inelutável pelos defensores do Iluminismo e, por conseguinte, do Evolucionismo aplicado à sociedade, os valores e os costumes correspondentes ao mundo da cultura popular considerados ameaçados de desaparecimento passaram a merecer a defesa de inúmeros intelectuais que, em concorrência àqueles movimentos intelectuais, viram nas festas, na poesia, nos jogos, nas músicas e nas danças das classes subalternas, não só uma forma de resistência cultural, senão um sistema cultural de preservação do "espírito do povo" - base de muitos nacionalismos emergentes3.

Não demoraria muito para que o etnólogo inglês William John Thoms propusesse em Carta, publicada na Revista The Atheneum, em 1848, o termo folk-lore ("saber tradicional do povo") para designar os estudos das então chamadas "antiguidades populares". Desde então, folclore tornou-se sinônimo de "cultura popular", embora nem toda cultura popular seja folclórica. Mais recente, porém não menos complexa, é a relação do folclore e a cultura popular com o conceito de patrimônio cultural imaterial .

Com efeito, o termo "Cultura Popular" aponta para um "campo" de

\footnotetext{
${ }^{3}$ Os nomes de Herder e dos irmãos Grimm encabeçam a lista dos pioneiros no campo da cultura popular no romantismo alemão, a este respeito ver Chauí (1986); Burke (1989); Ortiz (1992); Prandi (1997).

${ }^{4}$ Além da formulação do conceito de cultura por Edward B. Tylor em 1871, institucionalizando o campo de estudos antropológicos; com a publicação das Regras do Método Sociológico, de Emile Durkheim, em 1894, o folclore sofreria um duro golpe que seria sentido ao longo dos anos. É sabido o quanto os termos Folclore, Cultura, Popular e Patrimônio Cultural são controvertidos e de difícil definição. Cada qual, merece uma discussão que, infelizmente, não pode ser feita em profundidade, neste momento.
} 
estudos com uma longa história de críticas, trocas e disputas entre pesquisadores filiados a abordagens modernas ou tradicionais pela hegemonia da área. Por tais razões, este campo não está circunscrito a uma única área de conhecimento, embora encontre grande receptividade no pensamento antropológico. Assim, pode-se pensar a cultura popular como uma "região epistemológica" privilegiada no interior das Ciências Humanas e Sociais, a qual faz fronteira com outros objetos e campos de conhecimento, ficando muita próxima das questões abordadas pelos estudos do folclore, do patrimônio cultural e da cultura nacional. Este texto tem como objetivo deflagrar uma reflexão epistemológica sobre o conceito de cultura popular e suas relações com o folclore e o patrimônio imaterial no contexto do pensamento social brasileiro 5 .

Combinando a perspectiva da sociologia da ciência com a da etnografia do pensamento, relaciono essas reflexões sobre a cultura popular ao projeto Foucaultiano da "arqueologia do saber", com destaque para a formação dos conceitos $^{6}$. Contudo, menos do que buscar regularidades discursivas o que se pretende é destacar a importância da "cultura popular" como um conceito totêmico, portanto, "bom para pensar" o processo de "formação discursiva" das Ciências Sociais no Brasil. 0 conceito pode ser visto, então, como um caminho possível para se pensar o desenvolvimento (futuro) de uma arqueologia da cultura popular no Brasil no sentido estrito do termo.

Roberto Machado nos lembra o débito de Foucault para com a epistemologia histórica de Georges Canguilhem, para quem o conceito constitui elemento privilegiado da atividade científica uma vez que este não é só um termo que encerra uma "ruptura epistemológica" com o senso-comum. Na verdade, o conceito comporta um valor cognitivo na medida em que orienta o olhar e 0 processo de interpretação do pesquisador na observação dos fenômenos, sendo "através dele que o discurso expressa a racionalidade que o caracteriza", declara Machado (1981, p. 23). Em outras palavras, o conceito constitui um "objeto" privilegiado capaz de promover um exercício fecundo de reflexão epistemológica

\footnotetext{
5Mais do que a manifestação empírica de um objeto qualquer eleito "autêntico" e símbolo das classes populares e/ou da identidade nacional, o discurso da cultura popular assume no tempo e no espaço sentidos diferentes no conjunto das práticas e representações literárias, artísticas e científicas que formam o campo discursivo das Interpretações sobre o Brasil, em geral, e do discurso das Ciências Sociais, em particular.

${ }^{6}$ Projeto este desenvolvido em As Palavras e as Coisas - Uma Arqueologia das Ciências Humanas (1987).
} 
sobre o campo discursivo da ciência? .

À luz destas considerações teóricas iniciais, a estratégia metodológica adotada consiste numa abordagem "histórico-estrutural", por meio da qual se pode identificar três fases constitutivas na formação do conceito de cultura popular no Brasil. A primeira fase, compreendida entre as décadas de 20 e 60, é marcada por grande disputa metodológica, entre os estudos folclóricos e a emergente sociologia paulista, a respeito da autoridade e legitimidade científica do campo. A segunda, desenvolvida no período que vai dos anos 60 até os 80, caracterizase pela ampla divulgação do conceito de cultura popular com um sentido acentuadamente político e ideológico. A terceira fase, a partir dos anos 90 , coincide com a revitalização do conceito de patrimônio cultural, principalmente no sentido de patrimônio imaterial quando então, efetivamente, a cultura popular parece adquirir significado etnográfico tout court. Tais fases devem ser compreendidas como pontos de um processo de "longa-duração" no qual elementos de um significado conceitual mesclam-se em outro, sugerindo certa impressão de continuidade, sem apagar, contudo, as mudanças de sentido sofrida pelo conceito ao longo do tempo. De resto, deve-se destacar o risco inscrito nesta abordagem dada a extensão de temas, problemas e objetos que envolvem o campo discursivo referente à cultura popular, permitindo assim, neste momento, apenas uma visão panorâmica e ao mesmo tempo direcionada às suas variações de sentido no pensamento das ciências sociais no Brasil.

\section{SOCIOLOGIA DO FOLCLORE}

Desde fins do século XIX, Sílvio Romero, Couto de Magalhães e outros, aparecem como os precursores dos estudos folclóricos no Brasil ${ }^{8}$. Estabelecendo um

\footnotetext{
${ }^{7}$ Este exercício de reflexão epistemológica pode ser complementado com outros nomes da tradição sociológica e antropológica francesa, tais como Durkheim (1989), Marcel Mauss (1979; 1981; 2003) e Claude Lévi-Strauss (1989), elevando a cultura popular à "categoria de pensamento". No Brasil, Roberto Cardoso de Oliveira (1988) produziu obra da mais alta relevância epistemológica para as Ciências Sociais, não ficando de fora sua proposta de uma meta-etnografia do pensamento antropológico. Outras contribuições podem ser encontradas nos estudos do sociólogo Pierre Bourdieu (1983) e na história conceitual, de Koselleck (1992).

${ }^{8}$ Os primeiros estudos folclóricos merecem, por si só, um estudo à parte que não pode ser desenvolvido neste momento. Contudo, vale a pena destacar o trabalho de Matos (1994) sobre Sílvio Romero, e o excelente artigo de Ribeiro (2006), sobre o folclore e sua relação com 0 "regional" no Brasil da virada do século XIX/XX.
} 
corte temporal a partir dos anos 20, momento em que o folclore torna-se "objeto" de interesse dos intelectuais brasileiros, os nomes dos paulistas Amadeu Amaral e, principalmente, Mário de Andrade, são sempre os mais lembrados quando se pretende caracterizar os estudos folclóricos no contexto do modernismo brasileiro. Nos últimos anos, inúmeros estudos têm destacado o papel de Mario de Andrade à frente da Secretaria de Cultura de São Paulo, quando então concebeu pelo menos dois projetos de grande relevância sociológica: de um lado, a Sociedade de Etnografia e Folclore, que funcionou entre os anos 1936-1939 tendo à frente da diretoria Dina Levi-Strauss, esposa do eminente antropólogo dos Tristes Trópicos, à época professor de sociologia na recém fundada Universidade de São Paulo; do outro lado, a elaboração do projeto que, futuramente, daria origem ao Instituto de Patrimônio Artístico e Histórico Nacional. A estes feitos somam-se os incontáveis estudos folclóricos do escritor de Macunaíma no campo das artes plásticas, música e danças dramáticas do Brasil. Florestan Fernandes (1978), em um balanço crítico da produção folclórica de Mário de Andrade, destaca a excepcional qualidade etnográfica e científica do modernista se comparada ao conjunto dos folcloristas brasileiros da época.

Durante os anos 40 e 50, o folclore era considerado um "tema quente". Tanto é verdade que se tornou movimento organizado, produtivo e influente no cenário cultural brasileiro segundo o estudo de Vilhena (1997). À frente desse movimento estava Renato de Almeida, um intelectual dinâmico e bem relacionado no meio político nacional, cuja atuação política e intelectual ainda espera um estudo à parte. Entre os anos de 1947 e 1964, a atuação da Comissão Nacional de Folclore e a Campanha em Defesa do Folclore Brasileiro não deixam dúvida quanto à importância política deste tema no cenário nacional, inclusive, na produção da Cultura Brasileira. No entanto, não demoraria muito para que os folcloristas passassem a receber inúmeras e severas críticas. 0 rigor científico, teórico e metodológico, exigido pela Sociologia a partir da sua institucionalização nos anos 30, não poupou críticas ao Folclore e suas pretensões à Ciência. Florestan Fernandes (1978, p. 45 apud JEANROY), defende que o folclore é "menos uma ciência à parte, que um método de pesquisa". As críticas ao caráter colecionador, descontextualizado, a-crítico e descritivo das pesquisas folclóricas constituem seu "calcanhar de Aquiles", quando vistas pela perspectiva das "Regras do Método Sociológico", de Durkheim. Acrescente-se a isto a crítica teórica segundo a qual os estudos folclóricos não ultrapassavam o nível das "teorias nativas". Embora Edson Carneiro defendesse o caráter dinâmico e contemporâneo do folclore, como 
sugere o título de seu livro de 1965, a imagem do folclore como uma atividade intelectual romântica, artesanal e, até certo ponto, exótica e tradicional, persistiria no discurso crítico da sociologia e da antropologia ainda por muito tempo. Maria Laura Cavalcanti e Luís Vilhena (1990, p. 88) observam que:

0 confronto entre a "escola paulista de sociologia", representada por Florestan Fernandes, e os folcloristas da CNFL nos revela um debate entre dois modelos distintos da ciência, modelos esses que apontam para diferentes projetos de "modernização" para o Brasil. Do ponto de vista da produção de conhecimento, a hegemonia obtida pelo primeiro modelo no campo das ciências sociais no decorrer desse período pode ser identificada como uma das causas da marginalização dos estudos de folclore.

A compreensão deste confronto exige sua contextualização histórica. Sem dúvida, passamos a entender melhor o papel da sociologia no processo de construção da moderna sociedade brasileira nos idos de 40 e 50, quando levamos em conta a presença marcante da ideologia do desenvolvimentismo implementada a partir do governo de Juscelino Kubitschek. Tal desenvolvimentismo, apoiado nos preceitos do planejamento racional e científico, influenciou até mesmo alguns movimentos artísticos da época (bossa nova, poesia concreta, arquitetura modernista), além dos novos estilos de vida que invadiram as metrópoles. Neste contexto, a associação do folclore à tradição transformou-o no porta-voz de um mundo anacrônico, incompatível com o projeto de construção da nação moderna que, por sua vez, prescindia cada vez mais da sua contribuição para o progresso. 0 enunciado de Arantes (2002, p. 54 apud Frade), segundo o qual "pensar a cultura popular como sinônimo de tradição é reafirmar constantemente a idéia de que sua Idade de Ouro deu-se no passado", é extensivo ao folclore. É significativo, portanto, o fato da distinção entre folclore e cultura popular começar a se estabelecer a partir dos anos 50. Renato Ortiz já destacou o papel desempenhado pelo ISEB (Instituto Superior de Estudos Brasileiros) nesta distinção. Também nesta linha de interpretação, Oliveira (1992, p. 72) declara: "a identidade entre 0 folclore e cultura popular se rompe no ISEB. Folclore passa a ser tradição; cultura popular, transformação. Cultura popular passou a significar um meio para atingir determinado fim, dar consciência ao povo". Se antes o folclore era visto como parte do processo de construção da nação, a partir da ideologia desenvolvimentista este adquire um sentido negativo. Pode-se dizer, inclusive, que passou a ser visto como uma expressão de atraso cultural. Não por coincidência, entre os tópicos dominantes no discurso dos isebianos está a questão da "situação colonial", 
denunciada por Corbisier (1959). Percepção essa intensificada a partir das ações promovidas pelos Centros Populares de Cultura (CPCs) da União Nacional dos Estudantes (UNE) nos anos 60. Paradoxalmente, a politização do conceito de cultura popular acentua a distinção com o folclore ao mesmo tempo disputa com ele a "aura" da autenticidade.

Contudo, embora implícito, o elemento que parece sustentar a distinção entre o folclore e a cultura popular consiste no desenvolvimento da sociedade urbana, culturalmente marcada por visões de mundo e estilos de vidas modernos. Neste momento, sem perder de vista a convivência de manifestações folclóricas e da indústria cultural no espaço urbano, o conceito de cultura popular será profundamente marcado pelas experiências artísticas e percepções políticas desenvolvidas na cidade; é o que observam, por exemplo, Magnani (1982) e Carvalho (1992).

\section{A CULTURA POPULAR COMO IDEOLOGIA POLÍTICA}

Curiosamente, poder-se-ia começar por analisar a segunda fase "históricoestrutural" do conceito de Cultura Popular apontando, como seria de se esperar, uma ruptura e não uma quase continuidade com a fase anterior, em vista do papel dos intelectuais vinculados aos CPCs da UNE. Esta paradoxal "ruptura-econtinuidade" reforça a imagem de situação liminar que parece tomar conta do ambiente intelectual da época onde a mistura de política com arte, vanguarda e marginalidade, consciência de classe e individualismo, não representam, necessariamente, valores antitéticos. A significação política do conceito de cultura popular é, neste período, por si mesma, enunciativa. Como tal, ela fala da cultura popular como discurso ideológico. Nesta perspectiva, a mobilização dos intelectuais, artistas e estudantes da época, sob muitos aspectos pode ser vista como um movimento organizado, crítico e influente, a exemplo do Movimento Folclórico, analisado por Vilhena (1997). Também aqui, os intelectuais se imbuíram de uma "Missão" e um "Projeto" na construção da Cultura Nacional. Em linhas gerais, cabe ao intelectual ou artista do CPC o papel de produzir uma arte revolucionária que promova a conscientização política do povo. Carlos Estevam (1963, p. 29-30), declara em seu "livro manifesto":

A cultura popular, essencialmente, diz respeito a uma forma particularíssima de consciência: a consciência política, a consciência que imediatamente deságua na ação política. Ainda assim, não a ação política em geral, mas 
ação política do povo. Ela é o conjunto teórico-prático que co-determina, juntamente com a totalidade das condições materiais objetivas, o movimento ascensional das massas em direção à conquista do poder na sociedade de classes.

Por sua vez, Ferreira Gullar (1965, p. 1) aprofundaria o sentido político inscrito na "missão" e "projeto" destinados ao intelectual frente à cultura popular. Diz o poeta:

A expressão 'cultura popular' surge como uma denúncia dos conceitos culturais em voga que buscam esconder o seu caráter de classe. Quando se fala em cultura popular acentua-se a necessidade de pôr a cultura a serviço do povo, isto é, dos interesses coletivos do país. Em suma, deixa-se clara a separação entre uma cultura desligada do povo, não-popular, e outra que se volta para ele e, com isso, coloca-se o problema da responsabilidade social do intelectual, o que obriga a uma opção. Não se trata de teorizar sobre a cultura em geral mas de agir sobre a cultura presente procurando transformá-la, estendê-la, aprofundá-la.

É como se a famosa $11^{a}$ tese de Marx contra Feuerbach (1978, p. 53) - "os filósofos se limitaram a interpretar o mundo diferentemente, cabe transformálo" - adquirisse ação performativa nos escritos dos antigos membros da direção do CPC. No Brasil, o Marxismo teve um papel hegemônico no contexto políticocultural dos anos 60, embora não fosse homogêneo. As diferenças de posições entre os intelectuais da época, por exemplo, entre gramscianos e frankfurtianos, ou mesmo no interior do "movimento cepecista" como mostra Garcia (2007), não impediu uma convergência de interesses em torno da idéia de Revolução. 0 próprio conceito de cultura popular ganhou um caráter classista identificado com o operário. Some-se a isto um conjunto de práticas e ações produzidas pelos movimentos contraculturais, feministas, étnicos e minorias. Por sua vez, o conceito de cultura em geral, e de cultura popular em particular, estabelecem estreita relação política com o conceito de identidade, sinalizando para as mudanças que estavam em curso?.

De resto, seriam divulgadas algumas obras de grande impacto nos estudos subseqüentes sobre cultura popular no Brasil, tais como: A Formação da Classe Operária Inglesa, do historiador inglês Edward Thompson (1963); A Cultura Popular na Idade Média e no Renascimento - O Contexto de François

\footnotetext{
${ }^{9}$ Dois autores cujos trabalhos tornam-se referenciais a partir de então são Fredrik Barth (2000) e Roberto Cardoso de Oliveira (1976).
} 
Rabelais, do teórico da literatura russo Mikhil Bakthin (1965); Os Intelectuais e a Organização da Cultura e Literatura e Vida Nacional, de Antônio Gramsci, ambos publicados em 1968. Em suma, neste contexto a questão da cultura popular continua um "tema quente", sendo pensada, discutida, problematizada e politizada em vários espaços da vida social e cultural do país, destaca Brandão (2000).

De fato, é nos anos 60 que o conceito de cultura popular institucionalizase no discurso artístico e científico, tornando-se relativamente autônomo em relação ao folclore. Por outro lado, outros conceitos passam a dividir o campo discursivo referente à cultura popular, principalmente aqueles denunciados pela sociologia frankfurtiana de Adorno, Hokheimer e Benjamin. Em outras palavras, os conceitos de indústria cultural, sociedade de massas e alienação, entre outros, passam a dividir o campo de investigação dos intelectuais e militantes da "arte revolucionária”. Assim Adorno (1986, p. 99) se expressa ao final de sua análise sobre a Indústria Cultural:

0 efeito de conjunto da indústria cultural é de uma antidesmistificação, a de um antiiluminismo (anti-Aufklärung); nela, como Hokheimer e eu dissemos, a desmistificação, a Aufklärung, a saber, a dominação técnica progressiva, se transforma em engodo das massas, isto é, em meio de tolher a sua consciência. Ela impede a formação de indivíduos autônomos, independentes, capazes de julgar e de decidir conscientemente.

0 modo como o conceito de cultura popular é concebido pelos intelectuais da época permite perceber algumas oscilações de sentido nos quais ora esta significa alienação, ora significa resistência, ora ainda significa a possibilidade de, nos termos de Bakthin e Roberto DaMatta, "carnavalização". Esta oscilação de sentido também seria dramatizada pelos intelectuais do CPC que vêem então, três modos de pensar a cultura como arte: arte do povo como equivalente do folclore; a arte popular como aquela relacionada à indústria cultural e característica dos meios urbanos; e, por fim, a arte popular revolucionária como sendo a arte produzida pelos intelectuais e artistas com o propósito de produzir a consciência de classe e, por conseguinte, a transformação da realidade social. Fica evidente que o uso feito pelos cepecistas do conceito de arte no lugar do conceito de cultura apresenta forte conotação "metodológica individualista" no plano de um discurso ideologicamente comprometido com as classes e o povo, reafirmando assim o sentido do intelectual como guia da vontade popular. 0 conceito de "cultura popular" assume então, no quadro do pensamento cepecista, uma função 
pedagógica e messiânica na medida em que se apresenta como condição para libertaçã $0^{10}$. Numa definição, para Ferreira Gullar (1965, p. 3-4):

A cultura popular é, em suma, a tomada de consciência da realidade brasileira. Cultura popular é compreender que o problema do analfabetismo, como o da deficiência de vagas nas Universidades, não está desligado da condição de miséria do camponês, nem da dominação imperialista sobre a economia do país. Cultura popular é compreender que as dificuldades por que passa a indústria do livro, como a estreiteza do campo aberto às atividades intelectuais, são frutos da deficiência do ensino e da cultura, mantidas como privilégios de uma reduzida faixa da população. Cultura popular é compreender que não se pode realizar cinema no Brasil, com o conteúdo que o momento histórico exige, sem travar uma luta política contra os grupos que dominaram o mercado cinematográfico brasileiro. É compreender, em suma, que todos esses problemas só encontrarão solução se se realizarem profundas transformações na estrutura sócio-econômica e conseqüentemente no sistema de poder. Cultura popular é, portanto, antes de mais nada, consciência revolucionária.

Se, antes, a cultura popular associada ao folclore visava à construção da nação, agora ela se aproxima da idéia da revolução. No extremo, tal postura significava que a cultura popular, vista como expressão das classes subalternas, era portadora de uma cultura "autêntica", "pura" e, portanto, menos corrompida. Contudo, o problema desta postura, outrora tantas vezes discutida e criticada, é que o "povo" ou o "popular", como principal ator social deste drama é, de certa forma, excluído. Entre os tempos áureos do folclore e o movimento cepecista nos anos 60, a oralidade sugere um continuum não entre o "fato folclórico" e a "arte do povo" ou a "arte popular", mas sim entre os intelectuais folcloristas e cepecistas que falam "por sobre os ombros" do "povo", enquanto porta-vozes do "popular".

Contudo, não há dúvida quanto à importância política e epistemológica do conceito de cultura popular a partir dos anos 60. Mais do que nunca, o conceito de cultura popular se erige em categoria de pensamento, o que nos termos de Durkheim e Mauss, abre espaço para o entendimento das transformações pelas quais passava o discurso das Ciências Sociais no contexto da assim chamada

\footnotetext{
${ }^{10}$ Vale lembrar o papel da Teologia da Libertação e da Pedagogia do Oprimido nesse período. A relação cultura popular / educação libertadora está na origem do Movimento e pode ser vista a partir dos manifestos da época. Ver Fávero (1983).
} 
sociedade complexa ${ }^{11}$.

A ampliação do significado do conceito de cultura possibilitou política e epistemologicamente ultrapassar a visão das diferenças culturais como decorrentes de uma suposta inferioridade intelectual e/ou racial entre os grupos sociais. Pressuposto defendido por Lévi-Strauss já em 1952, do ponto de vista cognitivo, cultura é um fenômeno democrático e universal. Desde então, observa Segato (1992, p. 19), "cultura passou a ser entendida como funcionando da mesma maneira para todos". Como será analisada a seguir, esta democratização da cultura parece repercutir de maneira densa e profunda nas Ciências Sociais hoje. Assim, a revitalização dos estudos no campo do folclore e das culturas tradicionais contemporaneamente se deve não só ao processo de ampliação do próprio conceito de patrimônio cultural reconhecendo o direito das manifestações imateriais, mas também em razão das orientações extraídas das conferências e dos organismos internacionais para o campo das políticas culturais a partir dos anos 1970. De resto, pode-se destacar ainda a projeção da antropologia brasileira no cenário internacional muito embora este seja um fenômeno comum a outros países como nos mostra Canclini (1997) com seus estudos sobre a América Latina ${ }^{12}$.

\section{ANTROPOlOGIA do PATRIMÔNIO}

A criação dos programas de pós-graduação strictu senso em Antropologia no Brasil, a partir dos anos 60, coincide com o processo de ressignificação do conceito de cultura, principalmente, na tradição norte-americana. A publicação das Interpretações da Cultura, de Geertz, nos idos de 70, representa um marco na história da antropologia, denominada por alguns, pós-moderna. Naquele momento, retomando a proposta malinowskiana de se apreender o "ponto de vista nativo", Geertz (1978, p. 25) destacava o fato de que o que os antropólogos interpretam são interpretações de segunda e terceira mão, pois "por definição, somente um 'nativo' faz a interpretação em primeira mão: é a sua cultura”. Desta maneira, a proposta da antropologia hermenêutica ou interpretativa procura resgatar, do ponto de vista fenomenológico, o significado da cultura inscrito no

\footnotetext{
${ }^{11}$ Este ponto pode ser observado nas análises de Sader \& Paoli (1986) sobre as classes trabalhadoras e de Rocha (2006) sobre a malandragem no Brasil.

12 Para uma análise das políticas culturais pós-70, ver Nussbaumer (2007). Quanto ao desenvolvimento da Antropologia no Brasil nas últimas décadas ver a pesquisa 0 Campo da Antropologia no Brasil, editada pela Associação Brasileira de Antropologia (2004).
} 
fluxo do discurso social nativo.

As discussões iniciais acerca do patrimônio imaterial, também denominado intangível, coincidem com as discussões em torno do significado antropológico de cultura no mundo contemporâneo. Haja vista o que diz Lúcia Lippi Oliveira (2008, p. 135): "nos dias de hoje, os discursos sobre patrimônio enfatizam seu caráter de construção ou invenção, derivado das concepções antropológicas de cultura, que passa a ser tomada como sistema simbólico, como estrutura de significado pelas quais os homens orientam suas ações". Também Mariza Peirano, durante o Seminário Folclore e Cultura Popular (1992), identificou este momento como um reencontro da Antropologia com o Folclore, depois de um longo período de hegemonia da Sociologia no campo das Ciências Sociais no Brasil, e de "ideologismo" político da cultura popular no período pós-60.

Contribui para esta aproximação da antropologia com o folclore, entre outras coisas, as tentativas de superação da biculturalidade, no sentido da incomunicabilidade entre a cultura erudita e a cultura popular. Contudo, em mundo complexo, massificado e fragmentado como o das sociedades contemporâneas, onde não se pode perder de vista o papel da indústria cultural, as fronteiras entre 0 erudito e 0 popular, o rural e 0 urbano, o tradicional e 0 moderno são relativizadas, mas não superadas. Apesar de todo avanço e ampliação do significado de cultura e das reflexões epistemológicas desenvolvidas no campo do pensamento antropológico contemporâneo, o conceito de patrimônio imaterial ainda parece direcionado, tendenciosamente, para o lado da cultura popular. De acordo com Márcia Sant’Anna (2001, p. 153):

Ao longo dos anos 70 e princípio dos 80 , várias recomendações internacionais encaminharam noções mais dilatadas de patrimônio cultural, para além da arquitetura erudita e do conjunto urbano de valor excepcional, no sentido da proteção de lugarejos definidos como 'reservas de modos de vida', 'das criações anônimas surgidas da alma popular' e, por fim, 'das obras materiais e não materiais que expressam a criatividade do povo.

A verdade é que, se a noção de patrimônio imaterial pretende corrigir parte das distorções presentes na idéia vigente de patrimônio cultural, a qual reconhece somente manifestações da arquitetura de "pedra e cal", então, por definição, patrimônio imaterial deve também ampliar seu campo de abrangência atingindo, inclusive, aquelas manifestações que em princípio fazem parte da chamada arte ou cultura erudita. Afinal, se a ênfase do patrimônio imaterial recai sobre o saber/ fazer, ao limitar seu escopo ao universo da Cultura Tradicional e Popular, tal como 
postula a recomendação da UNESCO aprovada em 1989, fica evidente o conflito de interpretações.

José Reginaldo Gonçalves chama a atenção para o fato de que patrimônio é uma categoria muito importante e que não se restringe às modernas sociedades ocidentais. Com a ampliação do sentido imaterial na noção de patrimônio, Gonçalves (2007, p. 111) observa que, "diferentemente das concepções tradicionais, não se propõe o tombamento de bens listados nesse patrimônio. A proposta é no sentido de "registrar" essas práticas e representações e de fazer um acompanhamento para verificar sua permanência e suas transformações". Evidentemente, não se trata de um "registro" feito nos moldes dos antigos folcloristas, muito embora seja notória a aproximação com a antropologia. A reanálise dos estudos folclóricos tem merecido, atualmente, uma atenção toda especial dos antropólogos. Sem cair no romantismo que caracteriza os estudos folclóricos passados, o que muda nessa nova abordagem da cultura popular à luz do conceito de patrimônio imaterial é a tentativa de restituir ou de dar voz ao "povo". Daí não parecer ocasional a profusão de estudos sobre performance no campo da cultura popular. Afinal, não só a expressão corporal, mas também a oral ganham enorme visibilidade e significação na antropologia da performance ${ }^{13}$.

Com isso, não se pretende eliminar o trabalho do antropólogo e do sociólogo na interpretação da "cultura popular". 0 que muda é a concepção mesma de "cultura popular" a partir da renovação epistemológica do conceito de patrimônio. A superação do "espírito museográfico", que caracteriza os estudos folclóricos do passado, abre a possibilidade de uma reflexão epistemológica sobre o papel das "teorias nativas" no pensamento antropológico contemporâneo.

Temos assistidos nos últimos anos inúmeros movimentos e processos de construção de identidades, revitalização de expressões culturais, enfim, ações que apontam para um conjunto de representações que designam um momento de resgate das tradições culturais. É sabido que, para que uma tradição permaneça existindo ela deve modificar-se. Neste sentido, uma justificativa para a retomada da tradição, da memória e dos processos de construção identitária, por meio do patrimônio imaterial, sem que isso signifique uma volta ao modelo folclorista, consiste no peso dado à criatividade.

\footnotetext{
${ }^{13}$ Em anos recentes, parece estar havendo uma aproximação da noção de performance com os estudos folclóricos, observa Bauman (1984). Processo esse que também pode ser notado no Brasil nos dossiês de algumas revistas antropológicas dedicados à cultura oral e performance.
} 
Aprofundando o sentido da Interpretação das Culturas, Roy Wagner (1981) postula que a cultura é uma invenção. Não no sentido de "ficção", mas como resultado de uma atividade criativa que envolve os antropólogos e seus "nativos". A cultura expressa um modo de pensar característico da sociedade ocidental: o estudo da cultura é também cultura, declara o antropólogo. A invenção da cultura, mais do que fruto da imaginação ociosa dos homens, consiste no resultado de uma convenção. Em outras palavras, entendemos 0 sentido da invenção da cultura porque experimentamos o significado da cultura da invenção. As palavras de ordem inventar, criar e construir aparecem como resultado de uma convenção social. Assim, da mesma forma que se espera dos cientistas sociais capacidade interpretativa, reflexiva e criativa, o mesmo princípio se aplica aos "nativos". 0 conceito de patrimônio imaterial é portador desta promessa na medida em que confia às pessoas uma "autoridade" (no sentido de autoria) que, atualmente, parece expressar mais as incertezas dos cientistas sociais do que o reconhecimento adquirido à luz das reflexões epistemológicas no campo discursivo. Tal conceito, portanto, amplia o escopo político e analítico da antropologia na medida em que, de um lado, reabilita o campo de estudos folclóricos e da cultura popular - 0 primeiro domesticado pela sociologia e 0 segundo ideologizado pelos cepecistas - e do outro lado, deixa claro ser esta uma estratégia epistemológica eficaz na disputa pelo campo discursivo nas Ciências Sociais. Isto só é possível graças ao processo de dessubstancialização que parece tomar conta de inúmeras categorias analíticas do pensamento social moderno. Em outras palavras, conceitos como "povo", "nação", "intelectual", "ciência" e "patrimônio" tem sofrido uma revisão conceitual como nos sugere Laurent LéviStrauss (2001) para o caso do "patrimônio imaterial".

Um bom exemplo disto é a publicação recente do antropólogo Márcio Goldman (2006). Neste trabalho o autor desenvolve, logo na introdução, toda uma argumentação a favor das práticas discursivas do nativo na construção de um conceito de democracia política. Segundo o antropólogo (2006, p. 36):

...é estritamente necessário passar a encarar as práticas nativas (discursivas ou não discursivas) sobre os processos políticos dominantes como verdadeiras teorias políticas produzidas por observadores suficientemente deslocados em relação ao objeto pra produzir visões realmente alternativas, e usar essas práticas e teorias como guias para a análise antropológica.

Parece-me ser exatamente isto o que representa o conceito de patrimônio imaterial quanto ao que as pessoas pensam sobre a sua cultura. Inversamente ao 
processo político do CPC nos anos 60, o patrimônio fornece modelos de cultura popular alternativos e criativos para a interpretação antropológica de problemas ou fenômenos simétricos ${ }^{14}$.

Em suma, se antes o conceito de cultura popular esteve relacionado num primeiro momento ao folclore e à nação, e num segundo momento ao Movimento CPC e à idéia de Revolução, agora este parece estar se aproximando da idéia de performance em tempos de globalização. Inscrito nesta sugestão há um conjunto de questões a serem discutidas no futuro. Contudo, vale ressaltar que a tarefa arqueológica de compreender as mudanças de sentido (da estrutura à interpretação fenomenológica) sofridas pelo conceito de cultura popular abre a possibilidade de garantir a "autoria" do discurso popular, ao mesmo tempo em que se evita o perigo do "deslize semântico", do qual os conceitos podem ser vítimas, denuncia Durham (1986). Numa escala mais ampla, é a natureza mesma das Ciências Sociais, em geral, e da Antropologia, em particular, que está sendo problematizada.

Assim, a trajetória do conceito de cultura popular no campo das Ciências Sociais insinua uma possibilidade de leitura a partir do modelo levistraussiano desenvolvido no Pensamento Selvagem. Lévi-Strauss postula a existência de dois modelos de ciência, uma abstrata e outra concreta, uma racional e científica, outra sensitiva e artesanal. Uma, tem como modelo o engenheiro, a outra, o bricoleur. Aplicadas às Ciências Sociais, guardadas as proporções, a Sociologia aproxima-se do modelo racional, abstrato e científico, inclusive, exigindo rigorosos procedimentos metodológicos, quantitativos e explicativos; o Folclore, sugere claro parentesco com a atividade intelectual do bricoleur, pois, declara Lévi-Strauss (1989, p. 33), "ele se define apenas por sua instrumentalidade e, para empregar a própria linguagem do bricoleur, porque os elementos são recolhidos e conservados em função do princípio de que "isso sempre pode servir". À luz destas considerações podemos ampliar o escopo desta investigação sugerindo ainda um terceiro nível de operação intelectual no qual se situariam a Antropologia e 0 conceito de Cultura Popular. Oscilando entre o rigor metodológico defendido pela Sociologia e a atividade etnográfica - se se pode dizer, bricoleur, experimentada no trabalho de campo e próxima da experiência folclórica - é que a Antropologia e a Cultura Popular se encontram, para além do bem e do mal. A aproximação recente da antropologia com o folclore encontra no patrimônio, mais uma vez, um

\footnotetext{
${ }^{14}$ Aqui, a ênfase recai sobre o potencial analítico inscrito na idéia de patrimônio imaterial e não na política cultural de patrimônio de natureza institucional. A proposta de uma antropologia simétrica encontra-se em Latour (1994).
} 
meio termo para expressar em outras bases a cultura popular. Esta posição liminar, objeto de muitas críticas e sugestões é, talvez, o que nos permite compreender as dificuldades na definição do que é Cultura Popular.

\section{REFERÊNCIAS}

ADORNO, Theodor. "A indústria cultural". In: COHN, Gabriel. (org.). Sociologia. São Paulo: Ática, 1986.

BARTH, Fredrik. O guru, o iniciador e outras variações antropológicas. In: LASK, Thomke (org.). Rio de Janeiro: Contra Capa, 2000.

BAUMAN, Richard. Verbal art as performance. Illinois: Waveland Press, 1984.

BOURDIEU, Pierre. Sociologia. In: ORTIZ, Renato (org.). São Paulo: Ática, 1983.

BURKE, Peter. A Cultura popular na idade moderna. São Paulo: Companhia das Letras, 1989.

BRANDÃO, Carlos Rodrigues . A descoberta da cultura na educação - a cultura popular no Brasil dos anos 1960. In: A educação como cultura. Campinas: Mercado de Letras, 2007.

CANCLINI, Nestor Garcia. Culturas hibridas - para entrar e sair da modernidade. São Paulo: Edusp, 1997.

CAVALCANTI, Maria Laura Viveiros de Castro \& VILHENA, Luís Rodolfo. Traçando fronteiras - Florestan Fernandes e a marginalização do folclore. Estudos Históricos. Rio de Janeiro, vol. 3, n. 5, p. 75-92, 1990.

CHAUÍ, Marilena. Conformismo e resistência - aspectos da cultura popular no Brasil. São Paulo: Brasiliense, 1986.

DURHAM, Eunice. A pesquisa antropológica com populações urbanas: problemas e perspectivas. In: CARDOSO, Ruth (Org.). A aventura antropologia - teoria e pesquisa. Rio de Janeiro: Paz e Terra, 1986.

DURKHEIM, Emile. As formas elementares da vida religiosa - o sistema totêmico na Austrália. São Paulo: Edições Paulinas, 1989.

CARVALHO, José Jorge de. 0 lugar da cultura na sociedade moderna. Seminário folclore e cultura popular. Série Encontros e Estudos 1, MINC-IBAC, p. 23-38, 1992. 
CORBISIER, Roland. Formação e problema da cultura brasileira. $2^{\mathrm{a}}$ ed. Rio de Janeiro: ISEB, 1959.

ESTEVAM, Carlos. A questão da cultura popular. Rio de Janeiro: Tempo Brasileiro, 1963.

FÁVER0, Osmar (org.). Cultura popular e educação popular - memória dos anos 60. Rio de Janeiro: Graal, 1983.

FERNANDES, Florestan. O folclore em questão. São Paulo: Hucitec, 1978.

FERREIRA GULLAR. Cultura popular posta em questão. Rio de Janeiro: Civilização Brasileira, 1965.

FOCAULT, Michel. As palavras e as coisas - uma arqueologia das ciências humanas. São Paulo, Martins Fontes, 1987.

FRADE, Maria de Cáscia. "Evolução do conceito de folclore e cultura popular". Anais $10^{\circ}$ congresso brasileiro de folclore, São Luís 18 a 22 de julho de 2002, p. 48-61, 2004.

GARCIA, Miliandre. Do teatro militante à música engajada - a experiência do CPC da UNE (1958-1964). São Paulo: Fundação Perseu Abramo, 2007.

GEERTZ, Clifford. A interpretação das culturas. Rio de Janeiro: Zahar, 1978.

GOLDMAN, Marcio. Como funciona a democracia - uma teoria etnográfica da política. Rio de Janeiro: 7 Letras, 2006.

GONÇALVES, José Reginaldo Santos. Antropologia dos objetos - coleções, museus e patrimônios. Rio de Janeiro, Garamond, 2007.

KOSSELECK, Reinhardt. Uma história dos conceitos - problemas teóricos e práticos. Estudos Históricos, Rio de Janeiro, vol. 5, n. 10, p. 134-146, 1992.

LATOUR, Bruno. Jamais fomos modernos - ensaio de antropologia simétrica. Rio de Janeiro: Ed. 34, 1994.

LEACH, Edmund. Cultura/Culturas. In: Enciclopédia Einaudi, vol. 5: anthroposbomem. Lisboa: Imprensa Nacional-Casa da Moeda, 1985.

LÉVI-STRAUSS, Claude. O pensamento selvagem. Campinas: Papirus, 1989.

LÉVI-STRAUSS, Laurent. Patrimônio imaterial e diversidade cultural - o novo decreto para a proteção dos bens imateriais. Revista tempo brasileiro. Rio de Janeiro, vol. 147, p. 23-27, 2001.

MACHADO, Roberto. Ciência e saber - a trajetória da arqueologia de Foucault. $2^{\text {a }}$ 
ed. Rio de Janeiro: Graal, 1981.

MAGANANI, José Guilherme. Cultura Popular - controvérsias e perspectivas. BIB. Rio de Janeiro, n. 12, 23-39, 1982.

MATOS, Cláudia Neiva de. A poesia popular na República das Letras - Silvio Romero folclorista. Rio de Janeiro: UFRJ-FUNARTE, 1994.

MARX, Karl. Teses contra Feuerbach. In: Manuscritos econômico-filosóficos e outros textos escolbidos. 2a ed. São Paulo: Abril Cultural, 1978.

MAUSS, Marcel. Antropologia.In: OLIVEIRA, Roberto Cardoso de (Org.). São Paulo: Ática, 1978.

MAUSS, Marcel. Ensaios de sociologia. São Paulo: Perspectiva, 1981.

MAUSS, Marcel. Sociologia e antropologia. São Paulo: Cosac \& Naify, 2003.

NUSSBAUMER, Gisele Marchiori (org.). Teorias \& políticas da cultura - visões multidisciplinares. Salvador: EDUFBA, 2007.

OLIVEIRA, Lucia Lippi. Os intelectuais e o nacionalismo. Seminário folclore e cultura popular. Série Encontros e Estudos 1, MINC-IBAC, p. 69-74, 1992.

OLIVEIRA, Lúcia Lippi. Cultura é Patrimônio - Um Guia. Rio de Janeiro: FGV, 2008.

OLIVEIRA, Roberto Cardoso de. Identidade, etnia e estrutura social. São Paulo: Perspectiva, 1976.

OLIVEIRA, Roberto Cardoso de. Sobre o pensamento antropológico. Rio de Janeiro-Brasília: Tempo Brasileiro-CNPq, 1988.

ORTIZ, Renato. Românticos e folcloristas - cultura popular. São Paulo: Olho D’Água, 1992.

PRANDI, Carlo. Popular. In: Enciclopédia Einaudi, vol. 36: vida/morte tradições gerações. Lisboa: Imprensa Nacional-Casa da Moeda, 1997.

RIBEIR0, Cristina B. Folclore e nacionalidade na literatura brasileira do século XIX. Tempo. UFF, Vol. 10, n. 20, pp. 155-170, 2006.

ROCHA, Gilmar. Eis o malandro na praça outra vez: a fundação da discursividade malandra no Brasil dos anos 70. Scripta, v. 10, n 19, p. 108-119, 2006.

SADER, Eder \& Paoli, Maria Célia. Sobre "classes populares" no pensamento sociológico brasileiro. CARDOSO, Ruth (org.). A aventura antropológica - teoria e pesquisa. Rio de Janeiro: Paz e Terra, 1986. 
SEGATO, Rita. Folclore e cultura popular - uma discussão conceitual. Seminário folclore e cultura popular. Série Encontros e Estudos 1, MINC-IBAC, p. 13-21, 1992.

TRAJANO FILHO, Wilson \& RIBEIR0, Gustavo Lins. 0 campo da antropologia no Brasil. Brasília-Rio de Janeiro: ABA/Contra-Capa, 2004.

VILHENA, Luis Rodolfo. Projeto e missão - o movimento folclórico brasileiro 1947-1964. Rio de Janeiro: FUNARTE-FGV, 1997.

WAGNER, Roy. The invention of culture. Chicago: The University of Chicago Press, 1981. 